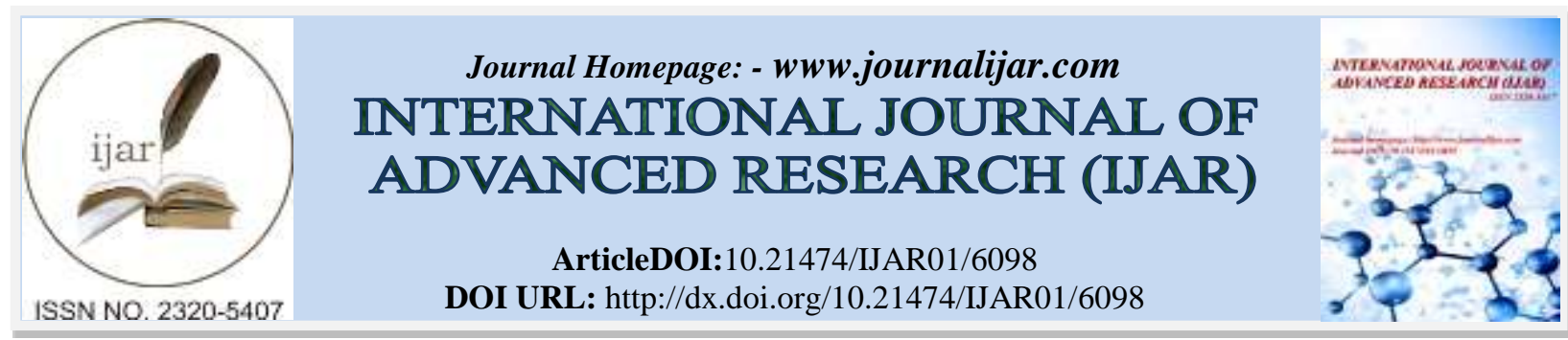

RESEARCH ARTICLE

\title{
RETROPERITONEAL ILIAC ARTERY ENDARTERECTOMY-A VIABLE ALTERNATIVE TO AORTOUNIFEMORAL BYPASS? IN POOR CARDIOPULMONARY PATIENTS.
}

Dr. S. Saravanan, Prof. K. Elancheralathan, Prof. G. Thulasikumar and Dr. C. Shanmugavelayutham. Dept of Vascular Surgery, Govt.Stanley Medical College , Chennai - 600001.

\section{Manuscript Info}

Manuscript History

Received: 18 October 2017

Final Accepted: 18 November 2017

Published: December 2017

Keywords:-

Revascularization, Retroperitoneal, Iliac Artery Endarterectomy .

\section{Abstract}

Introduction: to study the outcome and efficacy of retroperitoneal iliac artery endarterectomyin poor cardiopulmonary function.

Material and methods: this is a prospective study done in 15 patients with critical limb ischemia in the past two and half years (2015- 2017) who underwent extraperitoneal iliac artery endarterectomy with poor cardiopulmonary patients.

Results: fifteen patients underwent extraperitoneal iliac artery endarterectomy in this study. Most of them were males(14/15 - 93\%), with an average age of 63 years (age range 47-82 years). Cardiopulmonary comorbidities in form of ischemic heart disease were 73\%(11/15) and chronic obstructive lung disease - 27\%(4/15). All patients were subjected to iliac artery endarterectomy followed by iliofemoral bypass in 73\%(11/15), patch plasty $20 \%(3 / 15)$ and primary closure 7\%(1/15). Limb salvage in this study $85 \%(11 / 13)$ and patency $77 \%(10 / 13)$ during followup period of two years. Morality rate in this study $13.3 \%(2 / 15)$.

Conclusion: thus in selected group of aortoiliac occlusive disease patients with poor cardiopulmonary status retroperitoneal iliac endarterectomy remains one of the effective and safer procedures to consider.

Copy Right, IJAR, 2017,. All rights reserved.

\section{Introduction:-}

Although iliac artery (ia) endarterectomy has largely been replaced by bypass and endovascular options, open endarterectomy continues to play an important role in selected patterns of occlusive disease. $(1,2)$ purpose of the study is to analyse the outcome and efficacy of extraperitoneal iliac artery endarterectomy in poor cardiopulmonary patients.

\section{Material and methods:-}

This is a prospective study done in 15 patients with critical limb ischemia in the past two and half years (20152017) in our institution who underwent retroperitoneal iliac artery endarterectomy with poor cardiopulmonary function (all had poor ventricular ejection fraction or severe pulmonary disease). All these patients were not amenable for endovascular approach. 


\section{Results and discussion:-}

Fifteen patients underwent retroperitoneal iliac artery endarterectomy in this study. Most of them were males(14/15 $-93 \%$ ), with an average age of 63 years (age range 47-82 years). Cardiopulmonary comorbidities in form of ischemic heart disease -were 73\%(11/15) and chronic obstructive lung disease - 27\%(4/15).

Table 1:- Characteristics Of Patients Underwent Iliac Endarterectomy

\begin{tabular}{|l|l|l|l|}
\hline S.no. & \multicolumn{1}{|c|}{ Features } & \multicolumn{1}{|c|}{ Number } & \multicolumn{1}{|c|}{ Percentage } \\
\hline 1. & Mean age ( 47- 82 years) & 63 years & - \\
\hline 2. & Gender: a) male & $14 / 15$ & $93 \%$ \\
& \multicolumn{1}{|c|}{ b) female } & $1 / 15$ & $7 \%$ \\
\hline 3. & Cardiopulmonary risks: & & \\
& A) ischemic heart disease & $11 / 15$ & $73 \%$ \\
& B) chronic pulmonary obstructive disease & $4 / 15$ & $27 \%$ \\
C) combined & $8 / 15$ & $53 \%$ \\
\hline
\end{tabular}

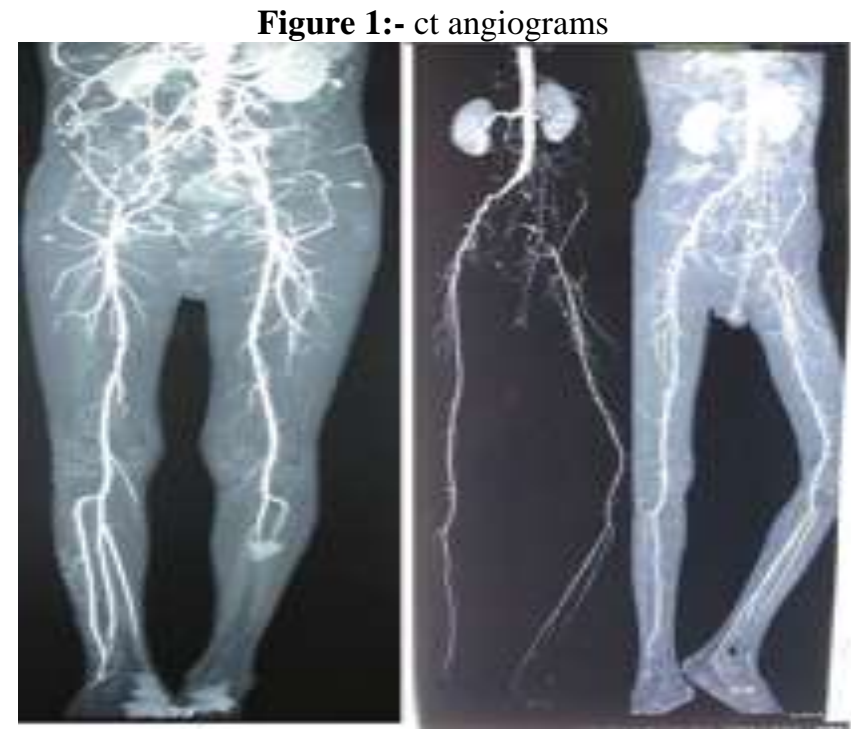

\section{Procedure:-}

All patients were subjected to iliac artery endarterectomy followed by iliofemoral bypass in $73 \%(11 / 15)$, patch plasty 20\%(3/15) and primary closure 7\%(1/15). Fifteen endarterectomies were performed and categorized into three groups: (1) combined common iliac artery and external iliac artery endarterectomy $(6 / 15 ; 40 \%)$; (2) external iliac artery endarterectomy (2/15; 13\%); and (3) aortic and common iliac artery endarterectomy (n 7; 46\%). Surgical adjuncts were performed in complement to these groups of iliac endarterectomy as follows: common femoral artery endarterectomy $(9 / 15 ; 64 \%)$;iliofemoral bypass in $73 \%(11 / 15)$, patch plasty $20 \%(3 / 15)$ and primary closure 7\%(1/15). Majority of iliofemoral bypass done after eversion endarterectomy $80 \%$ (9/11). 
Figure 2:- Oprative procedures
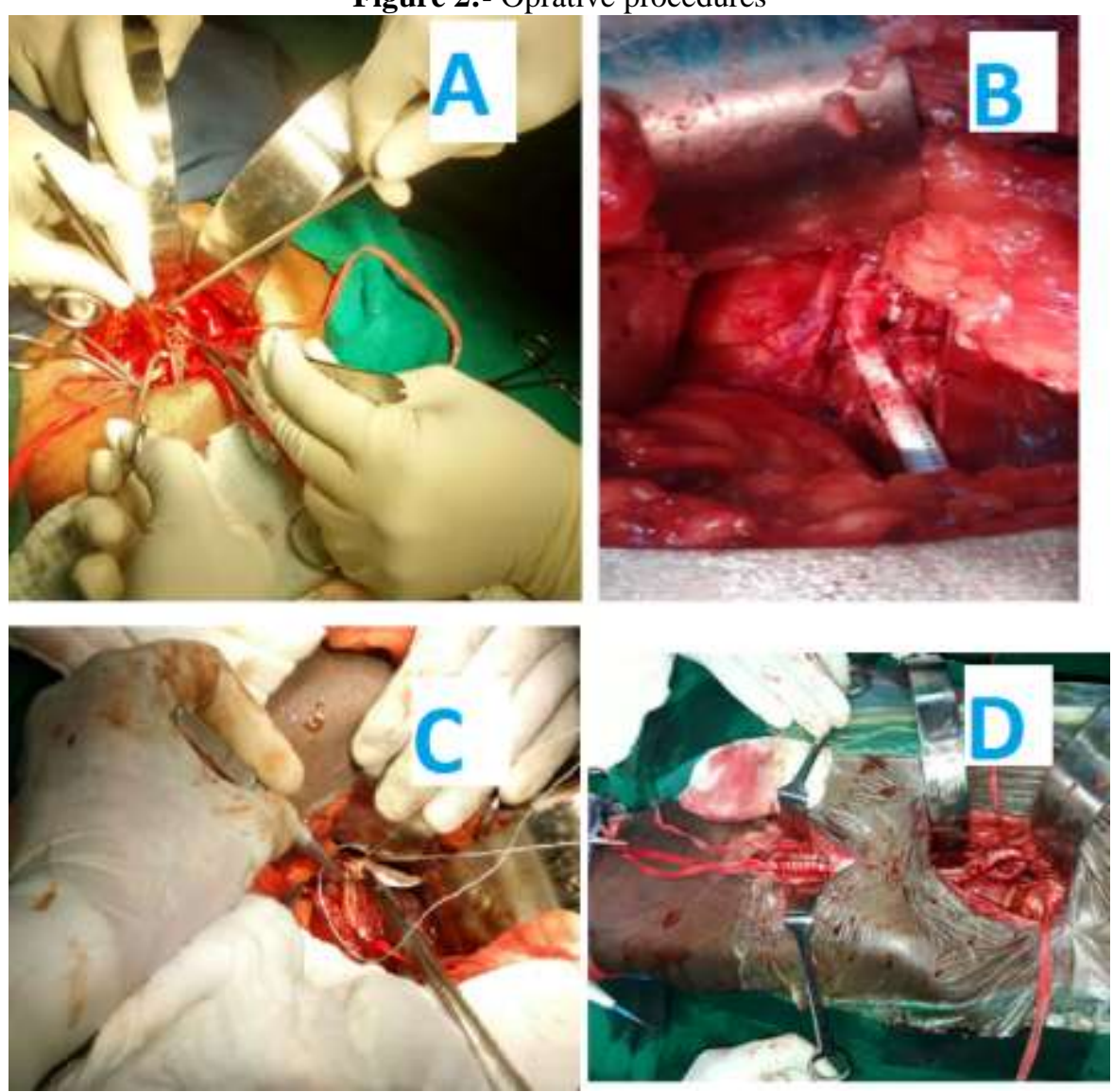

1. Iliac endarterectomy.

2. iliac-graft anastomosis.

3. patch plasty d) iliofemoral bypass.

An advantage of iliac endarterectomy is the variety of additional adjuncts that may be applied during theprocedure in this context, endarterectomy provides operative flexibility, allowing for adjustments to be made according to operative findings; for example, iliofemoral bypass can be performed if the backflow is inadequate.(3-5)

iliac endarterectomy offers an alternative for managing iliac occlusion, although common iliac artery exposure or a limited bypass may still be required. Further advantages of iliac artery endarterectomy over aortofemoral Bypass include avoiding aortic exposure and crossclamping to reduce cardiac stress. Endarterectomy may improve erectile function by opening stenotic hypogastric artery orifices. Advantages of extraperitoneal approach includes reduced respiratory complications owing to a less painful incision, reduced postoperative ileus, and reduced formation of intra-abdominal adhesions. $(6,7,8)$

Table 2:- Procedures And Outcome

\begin{tabular}{|l|l|l|l|}
\hline S.no. & \multicolumn{1}{|c|}{ Features } & \multicolumn{1}{|c|}{ Number } & \multicolumn{1}{c|}{ Percentage } \\
\hline 1. & Procedures: & $11 / 15$ & $73 \%$ \\
& A) Iliofemoral & $3 / 15$ & $20 \%$ \\
& B) Patch plasty & $1 / 15$ & $7 \%$ \\
\hline 2 & C) Primary closure & & \\
& Outcomes: & $11 / 13$ & $85 \%$ \\
& A) Limb salvage & $10 / 13$ & $77 \%$ \\
& B) Patency & $2 / 15$ & $13.3 \%$ \\
\hline
\end{tabular}


Limb salvage in this study $85 \%(11 / 13)$ and patency $77 \%(10 / 13)$ during followup period of two years. All the patients with limb salvage were free of rest pain and ulcer. Two had major amputations in form of one below knee and one above knee amputation following graft thrombosis and sepsis.

Morality rate in this study $13.3 \%(2 / 15)$, both died of myocardial infarction ( one during postoperative day 8 and other during followup period at 4 th month). Similar study by natrajan et al on 2008 shows similar patency(88\%) and mortality rates ( $4.3 \%$ _procedure related mortality)

\section{Conclusion:-}

Applied selectively to these group of patients and with the use of surgical adjuncts tailored to the patient's needs, based on operative findings, endarterectomy continues to provide good long-term patency with limited morbidity and mortality.(9-11)

Thus in selected group of aortoiliac occlusive disease patients with poor cardiopulmonary status extraperitoneal iliac endarterectomy remains one of the effective and safer procedures to consider.

\section{References:-}

1. Use of extraperitoneal iliac artery endarterectomy in the endovascular era , natarajan , selvakumar, vascular. 2008 nov-dec;16(6):310-5.

2. Haimovici's vascular surgery, 6edition

3. Hallet's comprehensive.vascular.and.endovascular.surgery, 2nd edition.

4. Rutherford's vascular surgery, volume- $2,8^{\text {th }}$ edition.

5. Wesley s.moore's vascular and endovascular surgery, $8^{\text {th }}$ edition

6. Dos santos cj. Endarterectomy. J cardiovasc surg 1976;17:107-28.

7. wylie ej. Thromboendarterectomy for arteriosclerotic thrombosis of major arteries. Surgery 1952;32:275-92.

8. Brewster dc, darling rc. Optimal methods of aortoiliac reconstruction. Surgery 1978;84:739-48.

9. stoney j, reilly $\mathrm{lm}$. Endarterectomy for aortoiliac occlusive disease. In: ernest cb, stanley jc, editors. Current therapy in vascular surgery. Philadelphia: decker; 1987. P. 157-60.

10. King rb, myers ka, scott df, devine tj. Aorto-iliac reconstructions for intermittent claudication. Br $\mathrm{j}$ surg 1982;69:169-72.

11. Freeman ne, leeds fh. Operations on large arteries: application of recent advances. Calif med 1952;77:229-33. 